The result is a brilliant non-specialist introduction to the ways in which "the wiggles carry news about the deep interior of the Earth". It can be used as an elementary text in seismology, as a primer for non-seismological Earth scientists or by the layman who seeks a lucid account of the subject; for each of these audiences, not the least of its strengths is that it takes trouble to explain those fundamental principles and ideas (for example, the nature of direct and inverse problems) that so many authors of even basic texts mistakenly take for granted.

Peter J. Smith is Reader in the Department of Earth Sciences at the Open University, Milton Keynes, and editor of Open Earth.

\title{
Carbon dioxide and climate (and journalism)
}

\section{John S. Perry}

Future Weather and the Greenhouse Effect. By John Gribbin. Pp.302. ISBN 0-440-02498-6. (Delacorte Press/Eleanor Friede: 1982.) \$15.95.

JOHN GRIBBIN essays a formidable task: to explain the genesis, mechanisms, history and probable future course of Earth's climate in some 300 pages of non-technical prose. His presentation is admirable in its design and broad thrust, but he has left some nasty booby traps for the unwary reader.

Over the lifetime of our planet, atmosphere, climate and life have evolved together. Climate has varied throughout the long history of the globe, and the short history of man. Rapid changes in climate could have drastic consequences and are a

\section{NEURO- TRANSMITTER AGONISTS FROM BIOSEARCH}

\author{
BIOSEARCH offers a number \\ of unique neurotransmitter \\ agonists of recognized value. \\ All are natural products \\ isolated in our laboratories and \\ are of exceeding purity. \\ QUISQUALIC ACID \\ $416 x$ potency of glutamate \\ $\$ 60 / 10 \mathrm{mg} \$ 300 / 50 \mathrm{mg}$ \\ $\$ 500 / 100 \mathrm{mg}$ \\ IBOTENIC ACID \\ $22 x$ potency of glutamate \\ $\$ 60 / 10 \mathrm{mg} \$ 300 / 50 \mathrm{mg}$ \\ $\$ 500 / 100 \mathrm{mg}$
}

Inquire about additional glutamate and GABA agonists as well as other BIOPERFECT natural products.

\section{BIOSEARCH}

1281-F Andersen Dr.

San Rafael, CA

USA 94901

Tel. 415 459-3907

Telex 172 029BIOSEARCH

Circle No.07 on Reader Service Card. legitimate cause for concern in a world already uncomfortably dependent on crops from a few climatically favoured lands. The most important human influence on climate is likely to be an increase in atmospheric carbon dioxide from the combustion of fossil fuels; models of the Earth's atmospheric and oceanic systems project significant changes in the workings of the great heat engine that powers our winds and governs our climate. Future weather will be different, and mostly warmer.

However carbon dioxide "feeds" plants, farmers are clever and people will probably continue to starve or grow fat primarily because of society's aberrations, not those of the weather. Changing climate - whatever its origin - simply complicates our task of providing energy, food and a decent life for everyone on Earth.

Communication of this thread of understanding to the public would be a noble achievement. Indeed, Gribbin's attempt has certain points to recommend it. He wields a breezy, conversational style and has a journalist's eye for arresting details of personality and event. Moreover, his explanations of certain scientific concepts and research results are outstandingly clear and accurate. For example, his discussion of the greenhouse effect is a model of its kind, and the core of his outline of the general circulation is probably as good as can be achieved without recourse to mathematics.

Unfortunately, other flaws sadly vitiate the book's value and betray its promise. The introductory chapters are crammed with a motley assortment of climatic titillations - droughts and blizzards and ice ages - each hurriedly and simplistically linked to one or another meteorological abstraction. Jet streams, the circumpolar vortex and the Intertropical Convergence really make sense only in the context of the general circulation, an insight postponed until Chapter 3. By that point, the lay reader may find himself mixed up and turned off.

The major failing seems to stem from a mismatch between the nature of science and the demands of journalism. There is a popular misconception that scientists are people who look for answers. That's nonsense, of course: although they generally share a working consensus, scientists are at root people who like to ask questions and pose hypotheses. Bearers of all sorts of ideas are eagerly welcomed to science's great and never-ending party, and the climate corner of the affair - one pictures it as lying between the hors d'oeuvres and the bar - is particularly crowded.

Thus, climate vies with politics, economics and religion in the number and variety of theories per unit of fact. All attempt to explain some aspect of the behaviour of a complex and poorly observed heat engine employing turbulent working fluids, subject to changing forcing, and tampered with to an unknown extent. Variability on all time-scales is a natural and inherent characteristic of climate, so it is no wonder that plausible connections can be adduced between almost any hypothesized cause and virtually any climatic consequence. Few survive independent data and scrutiny, yet Gribbin appears ready to embrace almost any theory - one longs to sell him a used car. The Sun-weather relationships, for instance, to which many pages are devoted, have proven particularly fragile, and it is misleading to treat these empirical speculations as established facts. Physics should rule over statistics, and a treatise on climate should seek to present a sound consensus and be built upon critical scientific judgement.

Instead, the book seems to have been constructed with the help of a vacuum cleaner and a glue pot. One imagines the author pointing his nozzle into all the dusty corners of the village library and cheerfully pasting up with unbounded enthusiasm what ever comes down the pipe - trash and treasure alike. One scientist's solar-based forecasts have "invariably proved right", a judgement shared by few and contradicted a page later. The atomic bomb and manmade aerosols are brandished as precursors of an ice age. For some reason, one dubious claim of geomagnetic-climatic connections merits an entire chapter, while another naive misinterpretation of irrelevant observations "commands respect" in assessing $\mathrm{CO}_{2}$-induced climate changes. It is astonishing that Gribbin, a physicist by trade, swallows an outrageous claim that even an atmosphere totally opaque to thermal radiation could warm the surface by no more than $4^{\circ} \mathrm{C}$. Physics aside, hasn't he ever heard of the heat wave on Venus?

Future Weather and the Greenhouse Effect has many ingredients of a badly needed commodity - a well-balanced and comprehensive book on climate for the layman. The man in the street, however, would be best advised to look elsewhere for a balanced understanding of knowledge and speculation is this important and exciting area of science.

John S. Perry is Executive Secretary to the Board on Atmospheric Sciences and Climate, National Academy of Sciences, Washington DC. 